\title{
Acidentes de trânsito: uma visão qualitativa no Município de Campinas, São Paulo, Brasil
}

\author{
Traffic accidents: a qualitative approach \\ from Campinas, São Paulo, Brazil
}

Marcos S. Queiroz 1,2

Patrícia C. P. Oliveira 2

\footnotetext{
1 Centro de Memória, Universidade Estadual de Campinas.

Rua das Orquídeas 587, Campinas, $S P$ 13085-370, Brasil. msq44@uol.com.br 2 Departamento de Psicologia Médica e Psiquiatria, Faculdade de Ciências Médicas, Universidade Estadual de Campinas. C. P. 6111, Campinas, $S P$ 13081-970, Brasil.
}

\begin{abstract}
This article takes an interdisciplinary qualitative approach to the problem of traffic accidents in Campinas, São Paulo, Brazil. The authors begin by analyzing the "municipalization" (i.e., decentralization to the municipal level) of transport and traffic management in Campinas based on social representations by members of the local government's technical staff. Data demonstrate a significant drop in traffic accident mortality in Campinas in the last ten years. The findings illustrate how new transport and traffic policies had several positive effects. Special attention is given to the objectives, strategies, and obstacles dealt with by local government in the "municipalization" of traffic. The paper concludes by emphasizing the need for specific public policies to revitalize urban mass transportation, including special traffic safety educational programs.
\end{abstract}

Key words Traffic Accidents; Safety; City Planning

Resumo Este artigo focaliza, numa perspectiva interdisciplinar qualitativa, o problema de acidentes de trânsito no Município de Campinas. Ele começa analisando o processo de municipalização do transporte e trânsito no município, com base nas representações sociais de técnicos da Secretaria Municipal de Transporte. Alguns números são trazidos à tona para mostrar uma queda significativa de mortes no trânsito em Campinas nos últimos dez anos. Esses números demonstram que as políticas públicas implementadas nesse setor têm sido positivas em vários aspectos. Atenção especial é dada aos objetivos, estratégias e obstáculos encontrados pelo poder local no processo de municipalização do trânsito. O artigo conclui enfatizando que, além da municipalização, o Estado necessita implementar políticas públicas específicas consistentes, principalmente aquelas voltadas à revitalização do transporte coletivo e a programas de educação no trânsito, a fim de se poder avançar no controle do problema.

Palavras-chave Acidentes de Trânsito; Segurança; Planejamento Urbano 


\section{Introdução}

Este artigo focaliza acidentes de trânsito (AT) no Município de Campinas e avalia as medidas tomadas pelo poder público no sentido de controlar o problema. Para esse propósito, duas fontes de dados receberam atenção especial: As representações sociais de técnicos da Secretaria de Transportes do Município de Campinas (SETRANSP) e dados estatísticos coletados por essa mesma instituição.

Como instrumento de pesquisa, foi elaborado um roteiro de entrevista semi-aberto dirigido a técnicos da SETRANSP, focalizando as seguintes questões: a percepção do problema por parte de tais agentes; as políticas públicas que estão sendo implementadas; os principais obstáculos ao equacionamento do problema.

Foram entrevistados 14 técnicos do setor, incluindo os secretários da gestão atual e das anteriores. Parte das entrevistas, que duraram de uma hora e meia a duas horas e meia cada uma, foi realizada com horário marcado, entre os meses de março, abril e maio de 1999; outra parte foi realizada nos meses de maio, junho e julho de 2001. Um dos secretários ofereceu três extensas entrevistas, todas elas realizadas na Universidade Estadual de Campinas (UNICAMP), e foi quem apresentou o maior número de dados para essa parte da pesquisa. Todas as entrevistas foram gravadas e posteriormente transcritas.

Em outra oportunidade, realizamos uma análise bibliográfica sobre o tema "acidente de trânsito”, envolvendo estudos realizados no Brasil e no exterior (Marin \& Queiroz, 2000). Aqui, pelo limite de espaço, iremos direto à pesquisa de campo, sem nos referirmos especificamente ao estado-da-arte desta área acadêmica, lembrando ao leitor, no entanto, que se trata de um tema da maior importância, na medida em que é capaz de revelar aspectos significativos do comportamento humano e da cultura que o envolve.

\section{A situação de acidentes de trânsito em Campinas}

Campinas é um município com 927.000 habitantes, localizado no Estado de São Paulo, a $95 \mathrm{~km}$ de sua capital. Embora apresente uma renda per capita mais do que duas vezes maior do que a média nacional, ele apresenta traços relativos ao desenvolvimento econômico e social que são típicos da grande maioria dos municípios urbanos brasileiros de médio e grande porte: crescimento descontrolado, planejamen- to insuficiente e falta de recursos para dar conta de grande parte dos problemas sociais. Contudo, no que diz respeito aos problemas relacionados com o trânsito, o município tem apresentado uma verdadeira revolução, com uma melhora significativa nos índices de acidentes e de mortalidade.

A luta contra os problemas do trânsito iniciou-se de modo mais consistente em 1991, com a criação da Empresa Municipal de Desenvolvimento de Campinas (EMDEC). Em 1992, houve uma intensificação dessa luta, com a municipalização e, conseqüentemente, a transferência do controle da administração e gerenciamento do trânsito para o poder local, incluindo autonomia na fiscalização de infrações, aplicação de multas de trânsito e administração dos recursos arrecadados com essas multas. Nessa ocasião, a SETRANSP estabeleceu as seguintes metas básicas: reduzir os índices de AT, diminuir os óbitos causados por AT e melhorar a fluidez e a circulação, pela diminuição dos pontos de congestionamento.

O Programa de Educação e Segurança no Trânsito Urbano foi uma outra iniciativa importante promovida pela SETRANSP. Criado em de 16 de outubro de 1992 e implantado a partir de 1993, tem o objetivo de promover uma mudança comportamental na população, pedestre ou motorista, conscientizando-a a adotar a segurança no trânsito como valor pessoal e prioritário. Em seu interior, destaca-se o Programa de Educação e Segurança no Trânsito (PETE), que tem sido considerado modelo para outros meios urbanos no Brasil. O programa tem como objetivo promover uma mudança de comportamento da população em geral, por meio da conscientização da segurança como valor prioritário e relevante para a qualidade de vida.

Em função de tais medidas, juntamente com a aplicação do novo código de trânsito, que se tornou efetivo em janeiro de 1998, os dados da SETRANSP (SETRANSP/EMDEC, 2000) revelam uma melhora significativa nos índices de AT e, principalmente, na gravidade dos mesmos. O aumento de $28,3 \%$ no número de AT por 100.000 habitantes que ocorreu entre 1992 e 1999 não desmente esse fato, uma vez que esse período presenciou um aumento de $52,3 \%$ nos veículos em circulação, passando de 268.187 em 1992 para 435.719 em 1999. Este número equivale a uma média de 2,54 habitantes por veículo, uma proporção expressiva, equivalente à encontrada em países mais desenvolvidos. Cotejando com os dados levantados por Stevenson (1989), este número só perde para os Estados Unidos (1,9 habitantes por veículo), 
ultrapassando a França $(2,6)$ e o Reino Unido $(2,7)$. Se for considerado, nesse mesmo período, o índice de AT por 10.000 veículos, verificaremos uma queda de $15,7 \%$. O que chama a atenção, no entanto, é a queda expressiva de $53,4 \%$ no índice de AT com morte por 10.000 veículos, mostrando que a eficácia das medidas implementadas pela SETRANSP refere-se principalmente aos acidentes graves.

Em total compatibilidade com esse último dado, de 1995 a 1999, o índice de mortalidade no trânsito por 100.000 habitantes passou de 19,96 para 10,97, expressando uma queda de $45 \%$ em apenas cinco anos. Esse índice já é melhor do que o verificado nos Estados Unidos $(15,0)$ e França $(14,0)$ e não está muito longe dos encontrados no Japão $(8,0)$ e Inglaterra $(6,0)$ para o mesmo ano de 1999 (SETRANSP/ EMDEC, 2000). Das 104 mortes ocorridas em 1999, 41 foram de pedestres (o que corresponde a $39,42 \%$ do total) e 23 foram de ocupantes de moto (22,11\% do total). Em 1995, do total de 181 mortes, 100 corresponderam a pedestres e 12 a ocupantes de motos, o que equivale a $55,24 \%$ e $6,63 \%$, respectivamente. A queda nos índices de atropelamento também merece destaque. Para 10.000 veículos, o índice passou de 44 em 1992 para 20 em 1999, expressando uma queda bastante significativa de 54,5\%. É importante notar que, em um cenário de queda significativa no índice total de mortes ocorridas no trânsito, houve um aumento brutal de mortes entre condutores e ocupantes de motos, passando de 12 em 1995 para 37 em 1999, o que corresponde a um aumento de $209 \%$.

O conjunto desses números, com a exceção das mortes entre condutores e ocupantes de motos, revela o fato de que a política de municipalização do trânsito em Campinas tem sido muito bem-sucedida, colocando o município em posição privilegiada tanto em termos internacionais como nacionais. Os dados sobre mortalidade no trânsito em Campinas o posiciona em um patamar de país desenvolvido, em situação bem superior àquela dos demais municípios brasileiros. Para se ter uma idéia comparativa, com referência a AT com vítimas para 10.000 veículos, o índice exibido por Campinas, de 2,39, é $60,2 \%$ menor do que o de Brasília; 50,8\% menor do que o de Curitiba; $31,8 \%$ menor do que o de São Paulo e 25,0\% menor do que o de Porto Alegre (SETRANSP/EMDEC, 2000).

Os dados levantados pela SETRANSP revelam ainda uma concentração de AT e de atropelamentos com vítimas nos finais de semana (sextas-feiras após as 19h, sábados e domingos), mostrando uma forte tendência de corre- lação dos mesmos com as atividades de lazer. Em 1999, a proporção de atropelamentos nesses dias representou cerca de $50 \%$ do total. Os técnicos da SETRANSP explicam que, durante a noite, os AT são mais graves, porque, mesmo com um número muito menor de carros nas ruas, os motoristas tendem a correr mais e muitos dirigem alcoolizados. Os jovens entre 15 e 29 anos são as principais vítimas dos AT ocorridos no meio urbano de Campinas, correspondendo a 61,9\% dos casos fatais em 1999.

\section{Uma avaliação sobre a fase inicial da municipalização}

A criação da SETRANSP deve ser entendida como o início do envolvimento do setor público municipal com o problema de trânsito. Em 1992, um convênio com o governo estadual garantiu autonomia do município para administrar e gerenciar o trânsito e, com isso, iniciar uma política pública voltada a esse problema. Em 1994, a SETRANSP iniciou a implantação, em toda a cidade, de equipamentos eletrônicos, com o objetivo de combater o excesso de velocidade dos veículos. Campinas foi a primeira cidade brasileira a adotar equipamentos eletrônicos para o controle da velocidade dentro do sistema viário urbano. Juntamente com essa medida, o município tornou obrigatório o uso do cinto de segurança.

Em 1993, a administração municipal investiu cerca de $3 \%$ do orçamento do município em programas de segurança e educação no trânsito. Essa quantia, à qual se agregava o valor arrecadado pelas multas, era suficiente para pagar a mão de obra referente aos funcionários, como os agentes de trânsito e a equipe técnica da SETRANSP. Os agentes de trânsito que apóiam, orientam e fiscalizam o trânsito, com credencial para multar os infratores, são chamados de "amarelinhos". Nos casos de fiscalização em que ocorre ordem para parar o veículo com a finalidade de verificar a documentação, uso do equipamento de segurança (cinto ou capacete) e as condições do veículo, o serviço é feito pela Polícia Militar.

Para desenvolver determinados projetos, a SETRANSP encontrou outras fontes de financiamento junto à iniciativa privada. Alguns deles foram as campanhas publicitárias do uso do cinto de segurança, a sinalização da cidade (passando de 56 placas de orientação instaladas para 1.600) e a melhoria sanitária e de iluminação dos terminais de ônibus.

Um outro aspecto pioneiro introduzido nessa ocasião foi a prioridade dada às ações pre- 
ventivas, em parceria com outras secretarias do município. Com a Secretaria da Educação, foi desenvolvido o programa PETE, já mencionado. Com a Secretaria da Saúde, obteve-se, pelo Projeto Cidade Saudável, que os AT fossem considerados uma endemia, o que possibilitou trazer para o município um serviço de atendimento médico de emergência ao acidentado no trânsito, o SAMU (Serviço de Atendimento Médico de Urgência), além da adesão das áreas médica e paramédica ao levantamento estatístico dos acidentes. O SAMU foi implantado em 1994, com três ambulâncias altamente equipadas tanto nos aspectos tecnológicos como em recursos humanos, com equipe especializada em atendimento de emergência. Com a Secretaria do Meio Ambiente do Estado, foi estabelecido um convênio que tem permitido à EMDEC gerenciar e inspecionar veículos de fretamento (escolares, alternativos e táxis).

Com a implementação do Novo Código Nacional de Trânsito, o Município de Campinas intensificou ainda mais as medidas que já vinha adotando nessas duas últimas décadas para melhorar o trânsito e diminuir o índice de óbitos na cidade. As principais mudanças que ocorreram nas leis de trânsito com o novo código foram as seguintes: (a) no campo das infrações, a mudança no valor das multas, que passaram a variar de $\mathrm{R} \$ 115,00$ até $\mathrm{R} \$ 500,00$; (b) no campo da fiscalização, a questão da pontuação, em que a pessoa pode perder o direito de dirigir por um período de um até doze meses; (c) no campo do conteúdo, a introdução de capítulos que falam sobre pedestre, cidadania, direitos e deveres dos cidadãos e meio ambiente.

\section{As principais dificuldades no processo de municipalização}

No processo de municipalização do trânsito, vários obstáculos já foram contornados; outros estão em fase de poderem ser controlados. Alguns deles, no entanto, foram apontados pelos técnicos do setor como especialmente difíceis: Em primeiro lugar, a questão cultural, que promove - principalmente entre membros das classes sociais média-alta e alta - um individualismo contrário à conformidade à lei; em segundo lugar, a dificuldade de fiscalizar e punir algumas infrações, sendo a mais grave delas o dirigir alcoolizado; em terceiro lugar, a situação financeira da Prefeitura, em estado semifalimentar; em quarto lugar, a questão da disciplina do pedestre no trânsito; finalmente, o problema do grande índice de AT com o envolvimento de motocicletas.
No que diz respeito ao obstáculo cultural no trânsito, os técnicos entrevistados apontaram o cinismo e a hipocrisia de setores de classes sociais mais privilegiadas, em aliança com os meios de comunicação, como o principal problema. Tais classes sociais apresentaram-se como vítimas da "indústria de multa", propagando a idéia de que todo o trabalho desenvolvido pela SETRANSP seria para angariar recursos financeiros que serviriam para alimentar os déficits produzidos por uma possível má administração. Algumas associações de profissionais aproveitaram-se desse tipo de crítica para tentar boicotar as medidas de fiscalização da Prefeitura, por meio de ações na justiça, baseadas em três pontos fundamentais: a falta de aferição do equipamento nos locais de implantação, a falta de licitação para o início dessa implantação e o sempre questionado poder de autuação dos agentes municipais. Embora alguns juízes tenham concedido liminares a motoristas para efeito de licenciamento de veículos, a Prefeitura venceu praticamente todas as ações no julgamento do mérito.

Após alguns anos de resistência, a população cedeu à evidência de que a manutenção dessa melhoria na qualidade de vida estava estreitamente relacionada ao convívio com as multas severas contra as transgressões no trânsito. As medidas implementadas pela SETRANSP, em seu conjunto, adquiriram legitimidade quando a população percebeu que a sociedade como um todo estava sendo beneficiada com a queda significativa dos AT. Na campanha eleitoral à Prefeitura Municipal da gestão 1996/2000, o prefeito eleito posicionou-se contrário à política do trânsito da gestão anterior e prometeu rever os valores das multas. Quando, no entanto, logo após a sua posse, ele tentou desativar os radares até que uma nova política para o trânsito fosse estabelecida, encontrou resistência popular de tal ordem que não houve alternativa senão manter praticamente intacta a política anterior. Um dos ex-secretários dos transportes entrevistados expressa-se da seguinte maneira a respeito da resistência popular às multas: "Um grande obstáculo à revolução no trânsito promovida em Campinas diz respeito ao cinismo e à hipocrisia da classe média e dos meios de comunicação. O pobre que é atropelado não chega à mídia, mas a classe média chega como vítima da 'indústria de multa' montada pela Prefeitura. Se o cidadão vê ladrões impunes em todo o lugar, ele não se conforma de ser punido por uma pequena infração no trânsito. Muitas pessoas me perguntavam porque a gente teria que se preocupar tanto com as pessoas passando em sinal vermelho ao invés 
de ir atrás dos ladrões que estão soltos por aí. Algumas pessoas ficavam revoltadas em ter de pagar multa para alimentar a corrupção que eles viam no governo público. Então, nós levamos uns três anos para sensibilizar a população $e$ mudar seu comportamento nesse aspecto. No entanto, quando a população começou a perceber que, com menos AT, a dimensão social sairia ganhando, ela agarrou-se nisso. Hoje em dia, não há a menor possibilidade de haver um retrocesso na política de trânsito por nós iniciada".

Estabelecer uma lei geral e universal para o trânsito foi considerado pelos técnicos da SETRANSP como uma questão básica e fundamental para o desenvolvimento do programa. Se qualquer uma entre as várias categorias profissionais que entraram na justiça procurando isenção de multas no trânsito tivesse tido ganho de causa, todo o projeto estaria ameaçado. A associação profissional dos médicos foi a mais persistente nesse sentido. A esse respeito, um dos ex-secretários dos transportes entrevistados expressa a sua indignação diante do fato de que justamente os médicos - categoria profissional que deveria estar empenhada na preservação da saúde e da vida - tenham-se mostrado tão insensíveis a um programa fundamental de saúde pública: "Eu fui processado na cidade de Campinas pela associação dos médicos, dos engenheiros e dos advogados por causa dos radares. O caso dos médicos foi o que mais me abalou. Eles queriam aprovar um projeto na câmara (e quase conseguiram) para passar uma lei que os liberasse de multas de trânsito, porque eles achavam que tinham que andar depressa para dar atendimento aos seus pacientes. Isso mostra que eles não entenderam nada sobre o significado do nosso projeto, sobre o benefício que ele estava trazendo à sociedade, em termos de qualidade de vida e de saúde. Ao invés de abrir mais postos de atendimento, mais postos de primeiros socorros e mais ambulâncias de plantão, nós pretendíamos matar o problema na fonte. Até recentemente, a preocupação diante do AT era a de fazer uma área de traumatologia mais eficiente, de adquirir mais tomógrafo, etc. O problema é que muito médico que fazia duas ou três próteses por semana, com o cinto de segurança e os radares, passou a fazer duas por semestre, o que significou uma queda significativa na receita de seu ambulatório".

O segundo grande obstáculo mencionado pelos agentes entrevistados refere-se ao consumo de bebida alcoólica entre motoristas e a fragilidade da lei para coibir essa prática. Até recentemente, a lei realmente protegia o infrator ao não outorgar força coativa ao policiamento e, com isso, obrigar o motorista suspei- to de estar alcoolizado a se submeter ao teste do bafômetro. Isso ocorria mesmo quando o indivíduo alcoolizado provocava um acidente ou até mesmo a morte de alguém.

Atualmente, o novo código de trânsito obriga o indivíduo a se submeter ao teste somente quando há acidente e vítima de trânsito. Quando não há vítima e houver indícios fortes de que o motorista esteja embriagado, o máximo que o policiamento preventivo consegue é levá-lo a uma delegacia de polícia, onde um médico do Instituto Médico Legal é convocado para atestar, em exame clínico, o seu estado. Tal procedimento é raramente realizado por insuficiência operacional da Polícia Militar.

Quando a prefeitura de Campinas iniciou um processo de fiscalização preventiva contra o ato de dirigir alcoolizado na região da cidade que concentra bares e boates noturnos, em fins de semana, ela encontrou séria resistência dos grupos econômicos que administram esses estabelecimentos, assim como da população de usuários. Vejamos o que diz um dos ex-secretários da SETRANSP a respeito: "Uma dificuldade que eu senti quando secretário foi com respeito à questão da bebida, ou seja, álcool e volante. É duro verificar que a lei protege o infrator. Pelo novo código, o motorista é obrigado a se submeter ao teste do bafômetro somente quando ele provocar um acidente com vítima. A questão do controle do álcool ao volante precisaria ser aprimorado pela justiça. Todo mundo sabe que, em fins de semana, o grande causador de acidentes são jovens na faixa de 18 a 30 anos, que causam AT por estarem alcoolizados. Mas eu vejo pouca iniciativa de fiscalizar e dar combate ao álcool ao volante, porque precisaria que as autoridades locais enfrentassem a classe média. A reação dela contra medidas preventivas desse tipo é pesada. Os donos dos bares e dos restaurantes vão dizer que você está cerceando economicamente a vida deles, que você os está perseguindo, que você quer uma cidade que não tem noite, etc. Ninguém é contra beber, o que não pode é beber e dirigir. O que precisa é a gente dar elementos culturais e comportamentais para as pessoas falarem 'eu vou beber à vontade e vou pegar um táxi para voltar para casa' ou, então, alguém da turma não vai beber e leva os outros para casa, que é o que ocorre no resto do mundo. Esse problema nem o código veio resolver. Você vê às vezes em vídeo ou em televisão o cara sendo algemado e preso nos Estados Unidos ou Canadá se ele estiver dirigindo bêbado. Aqui no Brasil, se você mostrar a algema para um jovem bêbado todos vão achar que houve um abuso de poder. Esse tipo de coisa precisa ser melhorado com educação e coragem para manter e aplicar 
medidas severas contra o infrator. O novo código foi só um começo".

A questão da fiscalização depende, em grande parte, de se estabelecer atribuições e responsabilidades entre as esferas de governo municipal e estadual. Tal questão permeia todo o processo de municipalização, envolvendo não só o trânsito e transporte, como também a segurança pública, educação e, especialmente, a saúde.

Os aspectos da fiscalização do trânsito e do transporte que não foram ainda municipalizados são considerados os mais difíceis de ser resolvidos. Os técnicos da SETRANSP consideraram a integração dos agentes municipais de fiscalização do trânsito (os "amarelinhos”) com a Polícia Militar - que obedece a uma diretriz do Estado -, como problemática e deficiente. Os "amarelinhos" têm a obrigação de fiscalizar, por exemplo, o uso do solo, o estacionamento proibido, a conversão indevida, a velocidade imprópria, a passagem por sinal vermelho. Não é considerada função do "amarelinho" parar o motorista para checar os documentos e verificar se ele está usando capacete ou se as condições do veículo estão adequadas, atribuições essas da Polícia Militar, que percebe o trânsito como apenas um problema entre muitos outros. A esse respeito, os técnicos da SETRANSP concordam em considerar como bastante eficiente o trabalho desenvolvido pelos "amarelinhos" e, ao mesmo tempo, deficiente o envolvimento da Polícia Militar com o trânsito. De acordo com um dos técnicos da EMDEC: "No que depende da Polícia Militar, nós temos muito menos eficiência, não propriamente por má vontade dela. O problema é que ela tem tantas outras atribuições na ordem pública, na questão da defesa do indivíduo, na segurança patrimonial, no combate à droga e ao crime, que ela não tem como se dedicar fortemente à questão do trânsito. Então você vê numa cidade como Campinas os motociclistas não usarem capacete, carros caindo aos pedaços, e muito pouco é feito para coibir essas práticas. Quando a Polícia Militar apreende um carro sem condições de transitar, ela não tem para onde levá-lo, porque freqüentemente os pátios estão lotados. Então, existem algumas dificuldades dessa natureza, que são de solução difícil, porque exigem mudança na lei. Só quando os 'amarelinhos' ou a polícia municipal exercer o papel de fiscalização no trânsito é que medidas preventivas poderão ser realmente eficazes".

A terceira grande dificuldade mencionada pelos técnicos entrevistados refere-se à questão financeira. Como uma empresa terceirizada pela Prefeitura, a EMDEC deveria ter seus serviços prestados pagos com os recursos provenientes do orçamento desta. Contudo, diante da crise no setor público municipal, muito pouco tem sido repassado da Prefeitura à EMDEC. Quando esta empresa foi fundada, cerca de $3 \%$ do orçamento municipal era-lhe diretamente repassado. Hoje, esse tipo de repasse não chega a $0,5 \%$, obrigando a EMDEC a sobreviver, principalmente, do dinheiro arrecadado de multas e, secundariamente, da tarifa mensal paga pelas empresas de ônibus e da arrecadação do sistema "zona azul" de estacionamento. O que é arrecadado, no entanto, mal chega a ser suficiente para cobrir os gastos básicos.

Um problema sério mencionado pelos técnicos da EMDEC nesse sentido diz respeito ao fato de que os recursos provenientes das multas de trânsito - o fator que responde por cerca de $90 \%$ dos recursos disponíveis pela SETRANSP do município - terem uma tendência de queda, simultaneamente ao aumento da disciplina, do controle e do cuidado do motorista. Nesse sentido, o próprio sucesso das ações da EMDEC mostra o efeito perverso de poder inviabilizar essa instituição.

A falta de condições políticas para se obter um melhor planejamento administrativo que permita à EMDEC uma visão de prazo mais longo é, de uma certa forma, análogo ao prestígio do ato médico clínico em detrimento do ato médico preventivo. Enquanto o primeiro produz um efeito visível e mensurável, o segundo produz um efeito invisível, que dificilmente traz dividendos políticos para quem o promove. A população reconhece e fica grata pela ação imediata da cura desenvolvida pelo serviço público, mas não costuma desenvolver um sentimento equivalente pela doença que não a acometeu. Tal motivo explica a relutância do poder público em desenvolver ações preventivas de longo prazo (Queiroz \& Viana, 1994).

A questão do comportamento do pedestre no trânsito também é considerada pelos técnicos da área como um fator complicado. Segundo o Novo Código de Trânsito, o pedestre é obrigado a seguir determinadas regras no trânsito, tais como: atravessar sempre na faixa de pedestre, de forma perpendicular; não andar por dentro de túneis; não andar em viadutos, etc. O não cumprimento das regras por parte do pedestre é caracterizada como infração que acarreta multa.

A grande discussão que se faz com respeito a essa questão é como os pedestres poderiam ser abordados quando cometem alguma infração; quais são os meios a serem desenvolvidos pelos municípios para preparar e sinalizar a cidade para os mesmos; como romper com o cír- 
culo vicioso que ocorre entre os municípios que não cobram nada de seus pedestres para não serem cobrados com relação à falta de infraestrutura destinada a eles; como superar o fator histórico de que, há apenas trinta anos, um município como Campinas, com características de cidade do interior, transformou-se em grande metrópole. O comportamento do pedestre em Campinas é similar ao visto no resto do Brasil, onde a grande maioria é ignorante do perigo representado pelo veículo motorizado e não sabe exigir seus direitos no trânsito, porque ninguém lhes cobra responsabilidade. É desse modo que se perpetuam as condições precárias de segurança para o pedestre no trânsito da cidade.

Para um dos secretários de transporte entrevistados, a questão do comportamento do pedestre no trânsito é complexa e o Novo Código do Trânsito, quando se dirige a essa questão, é completamente utópico. Para ele, multar o pedestre é algo totalmente impossível de ser realizado e, por isso, a questão deve ser enfrentada partindo-se da construção de obstáculos físicos que impeçam o pedestre de atravessar onde não deve.

Apesar da redução significativa nos índices de óbitos no trânsito de Campinas, o município vem apresentando um fenômeno muito sério, qual seja, o fato de que nos últimos dois anos triplicou o número de acidentes fatais com condutores de moto. Atualmente, mais de $90 \%$ das mortes no trânsito no município são de motoqueiros, embora eles representem menos de $10 \%$ do número total de veículos que circulam no município. Segundo um dos secretários dos transportes entrevistados, não é possível enfrentar esse problema de forma isolada, sendo necessário uma parceria entre as empresas que recrutam 'moto-boys' e a Prefeitura. Campanhas constantes deveriam reforçar o uso do capacete como um equipamento de segurança eficaz, assim como enfatizar medidas mais incisivas que possam modificar o comportamento inadequado dos motoqueiros no trânsito. Este secretário reconhece que muito mais do que está sendo feito deveria ser realizado a fim de controlar tal problema, inclusive um estudo que envolvesse a psicologia do adolescente no trânsito.

Uma medida importante lançada recentemente pela SETRANSP para enfrentar tal problema é o curso de segurança no trânsito que será oferecido pela EMDEC a todos os condutores de moto, com previsão de funcionamento a partir do final de 2001. O projeto, desenvolvido juntamente com a equipe do projeto PETE, tem por objetivo trabalhar com o piloto de mo- tocicleta as questões de segurança, uma vez que a maioria dos acidentes que acontece com essa categoria é causada pela falta do uso de equipamento de segurança (sendo o capacete o principal item) ou por situações associadas ao uso de álcool e a comportamentos indevidos ao trânsito. O primeiro passo para implementar esse trabalho tem sido buscar uma parceria das empresas que contratam "moto-boys", no sentido de estabelecer como requisito básico para a contratação desse tipo de funcionário o curso de segurança e pilotagem defensiva. Essa atitude também seria uma forma de a empresa estimular seus funcionários a refletir sobre o seu comportamento no trânsito e, assim, adquirir mais responsabilidade.

\section{Conclusão}

Este artigo mostrou, por uma perspectiva qualitativa centrada em entrevistas com técnicos em trânsito da SETRANSP, as políticas públicas que procuram promover o controle de AT no Município de Campinas. Alguns números, que expressam uma queda significativa nos índices de mortalidade no trânsito, foram analisados, tendo como referência os objetivos e as estratégias desenvolvidas pela SETRANSP. Mostramos que houve, efetivamente, uma melhora significativa nos índices de AT, principalmente no que se refere a acidentes envolvendo mortes. Contudo, o artigo preocupou-se em resgatar a dimensão subjetiva do problema e, desse modo, focalizar as percepções dos técnicos do setor, assim como as propostas, os dilemas e os obstáculos de ordem política, econômica e cultural que o envolvem.

Dentre as várias questões focalizadas no artigo a respeito da política local de trânsito em Campinas, três aspectos merecem ser retomados nessa conclusão: a precariedade do transporte coletivo, o problema de educação no trânsito e a questão de aplicação efetiva das leis existentes no novo código de trânsito.

Apesar de toda a vontade política que o $\mathrm{Mu}$ nicípio de Campinas tem mostrado no sentido de lutar contra os AT em geral e contra a mortalidade no trânsito em particular, muito pouco foi possível ser realizado na melhora do sistema de transporte coletivo. Há um reconhecimento unânime entre os técnicos entrevistados de que esse sistema continua precário, como sempre o foi, e que uma melhora substancial nessa área envolveria investimentos que se encontram fora do controle da esfera municipal.

Sem poder controlar este aspecto de um modo eficaz, o alcance das ações da SETRANSP, 
ainda que tenha sido amplo e significativo, torna-se limitado a longo prazo. Até o momento, as diretrizes da SETRANSP restringiram-se a estabelecer melhorias nas condições de tráfego de veículos, sem conseguir estabelecer uma política de controle capaz de melhorar o serviço de transporte coletivo em geral. A presença dos "perueiros" foi percebida como um fator que aumenta ainda mais a instabilidade de uma situação, que já é complicada. Tal questão, reconhecida como o ponto fraco das diretrizes do programa, foi eleita pelos técnicos entrevistados como altamente prioritária, uma vez que pode impedir avanços adicionais rumo ao equacionamento não só de AT, em particular, como também da qualidade da vida de moradores urbanos em geral.

Quanto à questão da educação no trânsito, houve um consenso entre os técnicos entrevistados de que, para prosseguir com as melhoras já alcançadas no trânsito do município, seria necessário concentrar esforços em um plano que envolvesse o indivíduo desde a escola primária até a vida adulta, sem interrupção. Merece destaque, nesse sentido, o programa PETE promovido pela SETRANSP nas escolas primárias do município, embora seja preciso dizer que se trata de um objetivo cujos resultados só poderão ser sentidos a longo prazo.

O novo código de trânsito prevê a questão da educação no trânsito, que exigirá um esforço considerável de integração, envolvendo vários órgãos federais, estaduais e municipais, tais como Ministérios e Secretarias do Transporte, da Saúde, da Educação, do Trabalho e da Justiça. Vimos que, de um modo geral, os convênios estabelecidos nesse sentido, foram muito bem-sucedidos, com a exceção das tentativas frustradas de se estabelecer um convênio com a Secretaria Estadual de Meio Ambiente.

$\mathrm{O}$ artigo mostra que regulamentar e implementar o novo código de trânsito exigirá um esforço considerável da sociedade e do poder público. Contudo, tal como aconteceu com o processo de descentralização do sistema de saúde, apenas os municípios de médio para grande porte apresentam condição de criar uma Secretaria de Trânsito e Transporte e gerar campanhas educativas continuadas nas escolas. Sem condições financeiras e técnicas para promover iniciativas nesse sentido, os pequenos municípios deverão permanecer por um tempo imprevisível à parte dessa importante questão de cidadania, até que haja uma política nos níveis federal e estadual nesse sentido.

A SETRANSP elegeu a intervenção na questão cultural referente a valores relacionados ao trânsito como um fator fundamental presente nas campanhas de prevenção de AT, em geral, e ao programa PETE, em particular. Contudo, os especialistas entrevistados foram unânimes em reconhecer que, sem multa, dificilmente poderia haver condições de se promover uma revolução cultural no trânsito. Os técnicos entrevistados admitiram consensualmente, nesse sentido, que um motorista bem treinado, que não provoca acidentes, é um indivíduo moldado pela rigorosa aplicação das leis. A educação, ou no mínimo a informação, serve apenas para que as pessoas conheçam a gravidade do problema e aceitem as restrições impostas pelas leis. O que realmente funciona, no entanto, é a certeza de que uma determinada infração será punida.

O cultivo do hábito de uso de cinto de segurança foi um aspecto mencionado para corroborar esse ponto. Um levantamento realizado pela SETRANSP concluiu que, em Campinas, as campanhas promovidas pela Prefeitura fizeram com que o uso do cinto chegasse a cerca de $20 \%$ dos motoristas. Quando o uso tornouse obrigatório e a infração passou a ser punida com multa severa, o uso chegou à cerca de $90 \%$ dos motoristas. A conclusão dos técnicos em Campinas é totalmente compatível com uma pesquisa conduzida pelo DETRAN (1996) que revela o fato de que as campanhas de esclarecimento sobre as vantagens do uso do cinto produziram, no Município de São Paulo, um aumento na adesão de $10 \%$ para $18 \%$. Quando a multa pesada começou a ser aplicada, o índice pulou para 95\% (Detran, 1996). Depois que se cria um ambiente em que a maioria usa o cinto de segurança e segue outras normas civilizadas ao volante, tudo fica mais fácil, porque aparece uma espécie de coerção social favorável à segurança.

Os técnicos entrevistados reconheceram também que, similarmente à questão do transporte coletivo, também no aspecto das multas, há necessidade de uma maior integração com as áreas de atuação estadual e federal. Para se punir um motorista infrator, por exemplo, seria necessário conhecer os atenuantes e agravantes constantes do seu prontuário, além de haver fiscalização eficiente e equipamentos técnicos que permitam mensurar a infração. Atualmente, a Polícia Civil não se encontra equipada em nenhum desses aspectos. Sem quadros treinados especificamente para o setor e sem equipamentos fundamentais como, por exemplo, o bafômetro ou uma rede informatizada, a maior parte dos infratores fica impune. No Estado de São Paulo, por exemplo, pouco mais de um terço das 313 CIRETRANS (Circunscrições Regionais de Trânsito) está in- 
formatizada, como informa o DETRAN (1996). Além da falta de equipamentos, os técnicos entrevistados apontaram que a ampliação da municipalização do trânsito passa necessariamente pela ampliação das funções exercidas pelos 'amarelinhos', assumindo responsabilidades hoje desempenhadas pela Polícia Militar.

Vimos também que a implementação de multas por meios eletrônicos de fiscalização de velocidade dos veículos foi um processo difícil em Campinas, em virtude, principalmente, das tentativas de algumas categorias profissionais de obter isenções e do protesto de comerciantes que se posicionaram contra a fiscalização em fins de semanas na região de bares e boates do município. Pode-se dizer que tal obstáculo foi contornado, pelo menos em parte. Apesar da questão da fiscalização ainda continuar precária, a aplicação de multas permanece com sua proposta original de universalidade, sem estabelecer exceções e privilégios.

Os nossos dados mostraram também que uma categoria de motoristas, a de motocicletas, necessita de uma atenção especial, uma vez que ela foi a única que não parece ter sido influenciada pelo conjunto de medidas implementadas pela SETRANSP. Pelo contrário, vimos que, entre 1995 e 2000, houve um aumen- to de $209 \%$ de mortes nos AT envolvendo motos. É evidente que o constante aumento desse número de veículos cadastrados no município não pode explicar uma cifra tão alta de aumento de mortes entre seus condutores e ocupantes. Um estudo que concentrasse uma atenção maior nesse tipo de fenômeno muito provavelmente teria que focalizar, em particular, a questão cultural, envolvendo jovens do sexo masculino, além das condições de trabalho dos entregadores de mercadorias.

Ao concluir o artigo, gostaríamos de enfatizar o fato de que a solução do problema de trânsito requer, em primeiro lugar, um olhar interdisciplinar que privilegie não só intervenções técnicas, mas também dimensões de ordem sócio-cultural. Em outra oportunidade, mencionamos que a maioria dos estudos sobre trânsito emprega métodos quantitativos, influenciados principalmente pela epidemiologia, e que há muito poucos trabalhos sobre o tema que utilizam métodos qualitativos (Marin \& Queiroz, 2000). Nesse sentido, o presente estudo insere-se no interior de uma proposta que considera estes últimos meios importantes para ampliar a compreensão desse fenômeno, permitindo, assim, uma intervenção mais eficiente do poder público.

\section{Referências}

DETRAN-SP (Departamento de Trânsito do Estado de São Paulo), 1996. Estatísticas de Trânsito. São Paulo: Secretaria dos Transportes do Estado de São Paulo.

MARIN, L. \& QUEIROZ, M. S., 2000. A atualidade dos acidentes de trânsito na era da velocidade: Uma visão geral. Cadernos de Saúde Pública, 16:7-21.

QUEIROZ, M. S. \& VIANA, A. L., 1994. Organização e gerenciamento dos serviços de saúde: Uma avaliação da experiência de Campinas. Revista de Administração Pública, 28:61-70.

SETRANSP (Secretaria de Transportes do Município de Campinas)/EMDEC (Empresa Municipal de Desenvolvimento de Campinas), 2000. Transportes \& Trânsito: Balanço 95-99. Campinas: Prefeitura Municipal de Campinas.

STEVENSON, D. K., 1989. Life and Institutions in the USA. Stuttgart: Klett.

Recebido em 21 de maio de 2001

Versão final reapresentada em 27 de agosto de 2001

Aprovado em 10 de dezembro de 2001 